\title{
Justice in Gender-Responsiveness? Psychological Dominations and Internalized Oppressions at a Women's Prison in the U.S. Tara Perry and Colleen Hackett *
}

What better way to control inmates; instead of using force to control them, you just change their minds and their thinking.

- Comment from anonymous prison official, referring to a gender-responsive program at a women's prison (November 2015)

Many prison officials in the United States (U.S.), much like the one quoted above, are acutely aware of the pressing need to legitimate their institutions to policymakers, the media, the public and themselves. The prison system is experiencing pressure to change those practices that are increasingly described as punitive, socially debilitating and psychologically harmful. From reducing reliance on solitary confinement and boot camps, to adopting so-called rehabilitative programming, the prison system in the U.S. is somewhat bending to the general call to "incarcerate less and rehabilitate the rest". For example, in the last few years the federal system has released nearly seven thousand prisoners convicted of nonviolent drug offenses (out of approximately 205,000 total federal prisoners) and has rhetorically recommitted to expanding vocational classes and psychological services, (i.e. drug education and mental health counselling). Although reformers and prison abolitionists alike, both inside and outside the prison, welcome many of these policy shifts, we maintain that this "rehabilitative turn" in punishment is deceptive and does little to dismantle the racist, classist, sexist, and ableist systems of oppression that enable the prison state to exist. Rehabilitation in prison is another technology in the social control toolbox that serves to victim-blame and shame the criminalized, while evading any discussion of the structural inequalities connected to criminalization (McCorkel, 2013). The first author is currently incarcerated at a women's prison in the Rocky Mountain region and the specific examples used in the second half of the paper will serve as a case study of how official definitions of rehabilitation are used to control prisoners and how those ideas are entangled with race, class, and gender. We hope this article will inspire readers to develop critiques of their own local prison or jail regime, and to similarly question how rehabilitation in these contexts might be superficially defined and limiting. 
Journal of Prisoners on Prisons, Volume 25(1), 2016

\section{INTRODUCTION}

Women's prisons (and jails) in the U.S., much like those in Canada, England, Australia, and New Zealand, are filled with marginalized bodies and systematically excluded and oppressed peoples. These facilities contain a disproportionate number of Black, Latina, and Native or Aboriginal women, and hold a predominantly working poor or working class population. Between 1997 and 2014, the female prison population in the U.S. increased by over $800 \%$, compared to a $400 \%$ growth in the male prison population (The Sentencing Project, 2016). The enforcement and intensification of drug policies (the so-called war on drugs) during the last four decades contributed to this astounding increase in women's incarceration rates (ibid).

Laws, policing practices, and sentencing disparities target and criminalize those who are excluded from dominant society, including drug-using women, as well as women who are economically disadvantaged, women of colour, and sex workers. This signals an ever-increasing trend to redirect women from the "social safety nets" of society to the expanding punishment system. Marginalized women are subject to surveillance and criminalization at the same time that they are failed by "helping" institutions. That is, marginalized women generally cannot rely on the police to protect their bodies or on social welfare agencies to meet their material needs. For example, Beth Richie (2006) documents the frequent abuses that women of colour experience when coming into contact with law enforcement officers, even when calling the police for help. This form of direct state violence is often inflicted because police (and the white publics) consider women of colour to be "transgressing racialized gender norms" or otherwise defying typical notions of ideal victimhood, usually reserved for middle- or upper-class white women (ibid, p. 143). Yet, the net-widening expansion of the war on drugs has resulted in disproportionate numbers of female prisoners of colour and female prisoners who are poor and lacking traditional education - a population who has higher rates of past and/ or current abuse than their non-incarcerated counterparts. Roughly $75-90 \%$ of female prisoners have experienced physical and/or sexual abuse, leading some scholars such as Mary Bosworth $(1999$, p. 26$)$ to comment that women's prisons contain a "community of victims rather than a collection of victimizers". The majority of people in women's prisons have experienced abuse as a child, as an adult, or both, and a great number of these survivors report receiving little to no help to address this trauma (Belknap, 2006). 
Punishing institutions perpetuate and exacerbate structural violence against women. This structural violence disproportionately positions women of colour and poor women to bear the brunt of racism, sexism, classism, and ableism. These groups are much more likely to live in hyper-policed neighbourhoods, go to under-resourced schools, be unrepresented in political conversations, and face great obstacles in securing stable sources of income and health care (Price, 2012). The penal system removes systematically disadvantaged women from their communities and their families, and uses tactics of control and exclusion to "manage" these populations. Once criminalized, women are subjected to a battery of assessments and tests to identify and measure their "criminogenic risks" to create opportunities "to change or transform the offender into a prudent responsible subject" (HannahMoffat, 2004, p. 40). For criminalized people of all genders, state apparatuses seek to enact power upon its wards but also through them; governing prisoners (and ex-prisoners) becomes the most politically viable when the "criminals" themselves adopt rationalities and subjectivities that align with state logics (Foucault, 1991; Rose, 1999). More than physically managing and forcibly containing women in concrete cells, the prison system also employs more subtle ways of controlling and sedating its wards (Cohen, 1985; Kilty, 2012). A successful governance strategy in a liberal democracy involves influencing targeted subjects to believe that their behaviours and thoughts are "risky" or unruly and to transform according to the dominant correctional expectations (Dean, 2010). It is through these more subtle means of control that we wish to critique a popularized form of power that is exercised on and through women in prison. We specifically take aim at the relatively new therapeutic regime in women's “corrections" known as gender-responsive programming.

\section{GENDER-RESPONSIVENESS IN WOMEN'S PRISONS}

A new trend is shaping modern correctional discourses and practices, particularly as it relates to incarcerated or post-incarcerated women (or people identified by the state as women) - gender-responsive programming. Although gender-responsiveness could be applied to all genders, to date it has been limited to female populations. This practice, imagined and advocated by mainstream feminist criminologists, asserts that male and female offenders have different life circumstances, histories, behaviours, 
and pathways to crime (Chesney-Lind and Pasko, 2004). Gender-responsive programming, as a recent stage in the evolution of penal reform, signals an intentional shift away from treating the criminalized "neutrally" according to their gender (Russell and Carlton, 2013). Paralleling the increasing number of women in prison over the past three decades, sociological and social work researchers have asserted the necessity of investigating the kinds of issues that criminalized women face before, during, and after their incarceration, on the basis that women have historically been ignored and made invisible by the social sciences (Belknap, 2006).

Gender-responsive intellectualism is informed by the "pathways" theory. Research on pathways theory demonstrates that the type, frequency and context of criminality are different for women than they are for men (Owen, 1998). For example, the most common pathway outlined by researchers, known as the "Street Woman" path, documents the typical criminalized woman as having run away from an abusive home as a child or young adult, and while enduring a life on the streets, she turns to drugs and/or alcohol to cope, and often finds herself in an abusive relationship and/or illegally hustling for money (e.g. sex work or petty economic crimes) (Daly, 1992). The research on pathways theory finds that the majority of women in the prison system have experienced emotional, physical, and sexual abuse as children and as adults (ibid). Although criminalized men also have high rates of past abuse, they have lower reported rates when compared to criminalized women. Studies on criminalized women's histories of abuse find that girls and women use criminalized survival skills to cope with the abuse, like running away from home as juveniles, using drugs, and/or sex work (Chesney-Lind, 2002). Much of this research is focused on the social psychological consequences of abuse and criminalization processes (e.g. low self-esteem, self-harm, substance use disorders). But at its theoretical core, pathways theory critiques larger social structures such as the patriarchal belief systems that enable and perpetuate the systematic degradation of girls, women, and genderqueer and transgender folks (Wattanaporn and Holtfreter, 2014). Some of these patriarchal beliefs include the false notion that cis-gender men are biologically or mentally superior to other gendered bodies, and have the right to more power than women and transwomen, or that "criminal" women are somehow too manly or sexually depraved.

Yet gender-responsive practices in the criminal legal system often ignore the literature that points to these entrenched social harms. Unsurprisingly, 
programs for women in prisons, jails, and/or reentry programs do not address issues of systemic power, domination, or structural oppression. Instead, these programs are operationalized through an individual therapeutic lens - that is, correctional practitioners focus on providing therapeutic "education" so that criminalized women can address their histories of abuse, fix their thinking (or their "emotional problems") and therefore reduce their future likelihood of committing another crime (Pollack, 2005). A few key feminist criminologists and psychologists, such as Bloom and colleagues (2003), have insistently pushed for the incorporation of gender-responsiveness into the prison system in the last decade, and have demanded more than just research and recognition of the problem; they directly collaborate with correctional facilities by designing women-centered therapeutic programs and by providing costly training seminars for potential facilitators at prison facilities and reentry centers. Indeed, "gender-responsiveness" is now the latest buzzword in correctional circles. This means that the collusion between the psychological sciences and the criminal legal system is being strengthened.

In his analysis on the relationship between psychology and power, Nikolas Rose asserts that the "psy-sciences" are a political force in that they serve and/or constitute varied state apparatuses of control. As Rose (1999, p. 7) argues, governance requires knowledge about human behaviour and the mind, resulting in a partnership with the psychological sciences to provide a new set of vocabularies that "enable the aspiration of a government to be articulated in terms of the knowledgeable management of the depths of the human soul". The state's increasing use of therapy within the department of "corrections" is problematic because this management of the soul is attempted within a coercive context. In prison settings, subjects are coerced into accepting (or at least placating) the penal-therapeutic regime under threat of losing one's parole or losing privileges, such as family visits. We refer to this dynamic as psychological domination, although we honour and acknowledge the ways in which prisoners actively resist "therapeutic governance" (McKim, 2008). Yet the state's attempts to exert control, particularly in psychological terms, are part of a broader set of dominating technologies that we wish to critically analyze.

The marriage between the psychological sciences and U.S. corrections is long-standing, and "gender-responsiveness" is just the latest articulation of decades-old cognitive behavioural therapy (CBT) programming. These 
therapies position "criminals" as guardians of their own destiny simply in need of a psychological toolkit that emphasizes "healthy" choices, better relationship decisions and getting rid of the "stinkin' thinkin" presumed to originate in the "criminal" mind. The assumption made by these programs and practitioners is that criminalized individuals, after mastering the art of appropriate decisionmaking, can freely choose the future course of their lives and are not affected by structural restraints, such as institutional racism or sexism - like employer discrimination, for example (Hackett, 2013). In CBT, individuals are stripped of their context and social positioning, while social inequalities are erased from institutional memory. Although we are not opposed to therapy or support groups, we are against the discursive erasure of structural violence that frequently happens in CBT. In both the practice of and in much of the scholarship on CBT and gender-responsiveness, inequalities and violence against marginalized communities become diluted or even removed from the conversation entirely (Pollack, 2010). Though it is useful to understand the ways that psychological harms impact prisoners, the implementation of treatment under the guise of gender-responsiveness in the penal system does nothing to address the varying ways that women are impacted and marginalized by overlapping oppressive structures. Prison therapy programs urge criminalized women to change their mindsets and behaviours, instead of working to unsettle patriarchal structures, misogyny and transmisogyny, racist and colonialist discrimination, and stopping gendered violence.

\section{AUTO-ETHNOGRAPHIC METHOD: A PERSONAL VIEW OF THE "INSIDE"}

In writing about one's experiences of being trapped inside the penal system, the method of autoethnography allows for the balance of both private reflection and academic analysis. Autoethnography, by nature, provides a framework through which personal crisis can be translated and transformed into useful research. As Sarah Wall (2008, p. 39) describes it, the method of autoethnography "offers a way of giving voice to the personal experience to advance sociological understanding". For a writer in active recovery from prolonged institutional violence, the approach of autoethnography can lend the reach and scope needed to extend personal experiences into the world as both a professional process and personal therapy. "Story-as-scholarship" through the conduit of autoethnography legitimates one's lived experiences as research. 
Regarding social justice issues related to incarceration and prison culture, there is great value in the use of autoethnographic expression by individuals who are directly impacted by oppression in that it can spark discussions about the issue with rich, concentrated contributions. No writing is ever purely neutral or value-free, no matter how heavily framed it is by scientific analysis and external objectivity. Rather, it is influenced by the writer's own beliefs and worldview, which is shaped by their positioning in society. Academics and others who are members of dominant society produce much of the research and knowledges related to the penal state and project their own ideas on how prisoners experience prison. Knowing this helps us appreciate the way that autoethnography can eliminate the assumption that a writer's analysis is bias-free and furthermore can provide a deliberate space for the inclusion of human expression, emotionality, and subjectivity in a way that invites others to engage consciously in the lived experiences of prison.

Taking an autoethnographic approach with this topic, the first author documented her experiences, observations, and meaningful conversations through personal journaling. ${ }^{1}$ These documents provided raw material for later reflection and analysis. During Tara's incarceration, writing was a way to cope with an otherwise unbearable condition. While her recordings of feelings, sentiments and interactions might not be considered "field notes" by traditional objectivists, over time they have accumulated into a useful supply of data for analysis. For example, while making herself emotionally, mentally and physically available to hold a space for the suffering of others around her, Tara found herself organizing the collective experience at the women's prison into something academically beneficial. She owes a great deal of respect and admiration to those she found herself suffering alongside. Therefore, it is her hope that she is able to help transform the collective prisoner experience into effective, positive social change.

Positionality plays a significant role in any research setting, especially in institutions in which isolation is substantial. After spending fifteen years in a relatively larger prison system of 900 prisoners located in a metropolitan area, Tara was transferred to a rural and geographically isolated facility that housed approximately 230 prisoners. She found herself grappling with the ability to relate to strangers, while also reshaping her entire perspective about "doing time", something she considered herself quite a champion at. Many factors made her both a part of and an outsider of her environment. 
Tara was placed in a strange tomb where well-established relationships and processes preceded her arrival. Sentence length, amount of time one has served, and one's crime (e.g., "violent" or "non-violent") tend to be the biggest defining factors of identity and social standing behind bars, and Tara quickly found herself teetering on many different lines. Although she had already served fifteen years, she was starting all over again like a new fish even after dwindling down a 66-year sentence in another facility. She arrived at the facility with just three years remaining. She did not bond fully with other prisoners in the ways she had before and yet she could personally identify with something about each individual's situation. At times, other prisoners accepted Tara, but at other times she was not received well by staff or other prisoners for reasons that ranged from her "deviant" gender identity and expression to her resistance to and struggle against oppression. Captured in this research reflection are the realities of those simultaneous experiences of closeness and tensions.

The Rocky Mountain Women's Prison (RMWP) ${ }^{2}$ is a facility that houses minimum, medium, and maximum-security custody levels and is located in a rural, isolated town in a Western state. The first author, after having served 15 years at a prison in her home state, was transferred to RMWP to serve her two remaining years before being released to parole. Her encounters and interactions at RMWP provide rich observations regarding systemic domination and oppression and serves as a comparative resource to the prison regime in her home state. The remainder of this article presents those experiences and observations that the first author collected over her time at the facility.

The instant I was ushered through the gates of the RMWP I was acutely aware that I had just crossed the threshold from one form of institutionalism into a new vortex of systemic domination. Directly after I underwent the very naked, cold intake ritual of stripping and showering ("de-verming"), with no time to reorient myself, I was sitting in front of an intake caseworker's desk. Suffering from mental and physical exhaustion, as well as shock, here I was being asked a list of invasive questions such as the details of my conviction, my history of childhood sexual abuse, and of course my sexual orientation. Unbeknownst to me at the time that the answers to these questions would be the guiding factors of my "programming" for the remainder of my stay there at RMWP. (Tara's personal observations, March 2014). 


\section{PSYCHOLOGICAL DOMINATION AT ROCKY MOUNTAIN WOMEN'S PRISON}

The "treatment" program at RMWP, based on gender-responsive CBT models, assigns women to one or more classes during their initial intake process. Based on an individual's situation and background, a case manager will assign a cocktail of classes for each prisoner to complete. This "individualized" treatment assigns women to generic classes that cover issues such as trauma recovery, addiction and healthy relationships. Completion of these classes in one's case plan becomes a determining factor in the correctional interpretation of the individual's "progress" within the facility and once available, in their release options (e.g. parole or community/halfway house placement). The classes revolve around a series of workbooks with prompt questions or "statement and answer" sections. This bulk curriculum appears to be the easiest, most convenient and affordable programming for large groups of individuals - a package deal, so to speak, for the prison to claim that they are offering individualized rehabilitation services. Not only is this method prudent for the prison, but it also allows for a closer and more intimate supervision over each prisoner. There exists a lack of confidentiality with respect to what prisoners reveal during these therapy sessions. The same caseworkers that run group therapy classes also hold weekly meetings with institutional administration, influencing and making decisions about individual prisoner statuses. This includes everything from women's housing and job opportunities to their community placement, making it unsafe to authentically disclose personal information in emotional processing groups. In this way, psychological domination is at work when women cannot find benefit in expressing themselves or fear that greater repercussions will be had if they say the "wrong" thing.

The content of these workbooks are geared toward changing women's distorted thinking and choice betterment. Themes include personal reactions, thinking or feeling patterns, behaviours, and choices. Practitioners of gender-responsive therapy often focus on "fixing" women's emotional problems and teaching them how to pick better, "healthier" relationships. Although this curriculum may give many women in prison tools to mentally and spiritually transform into their ideal selves, we argue that these therapies assume that criminalized women are emotionally out of control and suggest that women can choose whether or not they experience abuse. We argue 
that this "blaming the victim" rhetoric avoids directing the critical gaze on the violent patriarchal structures that allow interpersonal and institutional abuses to happen in the first place. The curriculum mobilizes assumptions about women in general, but more specifically the thought that poor or racially marginalized women are loose cannons, irrational or unruly (Faith, 2011). Additionally, this approach has left little to no room for the reflection of social and circumstantial impacts on a person. When prisoners at RMWP encounter issues in the prison, such as staff mistreatment for example, caseworkers reiterate that women have the "personal choice" to act correctly and assert that it is not ill-treatment we are receiving from staff. Responsibility is wholly shifted onto the individual and relieves the institution of any wrongdoing (Cruikshank, 1999).

I was one of a handful of women who received a write-up for breaking the "no talking in the hallway" rule. The rule itself and the handling of these bulk write-ups was blatantly arbitrary; the rule was not in the procedure book and a few of the write-ups just "disappeared" with staff intervention while several others were convicted heavily. I was in the latter category, losing my job and custody status as a result. When I communicated with my caseworker in a distraught state about my frustration over the issue all that I received was the same program-fed script about the very wrong personal choice I made to talk in the main hallway (to disregard the rules, essentially). There may have been some truth in that, however there was no rationalization regarding the disproportionality of the write up to the consequences, when, incidentally after filing an appeal against the writeup and the arbitrariness, the rule itself was completely repealed, resulting in staff no longer being able to use disciplinary action for anyone talking in the main hallway. Administration's formal response to this was clearly inconsistent with the response of my caseworker when at the time I sought out some sort of support or reasoning around the issue. (Tara's personal observations, October 2015).

Prison guards and staff members at RMWP also enforce rules that are based on assumptions about the nature of the "female offender", which emboldens the moralistic undertones of gender-responsive CBT. Women prisoners who are labelled as violent (either because of their conviction or because of physical altercations while incarcerated) and those who are 
labelled as sexually "risky" are contained and physically separated from the general population. Women who act outside the bounds of gendered norms (e.g. acting aggressively, using violence or engaging in self-defence) and those who defy conservative heterosexual mandates (i.e., engaging in samesex companionships) are likely to be penalized, shunned, and labelled as risky. Those who are housed in the most restricted hall at RMWP are placed there as a result of high levels of either violent or sexual "risk". Receiving a high score for riskiness could result from a single write-up for a physical altercation or incident of sexual activity, whether it be during incarceration or before incarceration while at a halfway house. Additionally, the bar for receiving a write-up is very low:

The fear of getting a write-up is so strong that it prevents us from engaging in meaningful interactions with friends. For instance, a close friend had lost her mother. Upon hearing this news, I stood there, awkwardly. I had the urge to offer my friend a hug, or at the very least, a hand on her shoulder. Doing so would have resulted in an automatic write up for a "sexual misconduct". Living under these conditions causes many at RMWP to shut off their empathetic selves completely. It causes isolation and even symptoms of madness. Friendships, after awhile, feel like a foreign place. I considered making my friend a sympathy card, but giving it to her must be done with great caution; if caught we would most likely get a "passing and receiving" (or "loaning and bartering") write-up. The impact for me would have been less severe, since I was the holder of several disciplinary actions, but risking trouble for my friend would only have compounded her grief. In many U.S. prisons, exchanging property or trading services is not allowed and can result in disciplinary action, though this seems to be arbitrarily enforced. (Tara's personal observations, July 2015).

This raises the issue of how different facilities adopt the praxis of gender-responsiveness, except in the important areas where gendered behaviour and social interactions differ. Policies that prohibit physical contact and also "passing and receiving" were originally established as anti-exploitation policies for mainly male prisoners. The "gender-neutral" universal enforcement of these rules within women's prisons creates more harm than it does good, for example by cutting off expressions of empathy and loading up prisoners' disciplinary records with frivolous infractions that 
prevent progress. The formal marking of such infringements can remove a prisoner's earned good time and can greatly jeopardize the likelihood that a prisoner may earn parole, if eligible.

Additionally, the consequences of receiving a write-up at RMWP are extreme. A woman who receives a "risky" write-up receives a minimum of 60 months (5 years) on the restricted hall, so even if an individual makes personal progress or displays positive behaviour, they cannot escape the limitations of the restricted hall. For a minimum of 5 years, those placed on that restricted hall are stigmatized and withheld from general population activities, like shared gym time and religious services, and are kept separate during mealtime. This locks women from the restricted hall out of most programs or activities, and enforces extreme control over both individual choice and movement. Individuals restricted to this hall, although withheld from facility activities, are required to attend the CBT groups prescribed within their case plans, meaning the workbook-driven classes tend to be their main source of stimulation or social interaction outside of the restricted living area. Prison guards and staff members limit opportunities for women on the restricted hall to socially interact with others. Women with relatively shorter sentences on the hall may start with no incentive to try and advance. Incarcerated women with long-term sentences are likely to internalize the grave "mistake" they have made and express feeling "hopeless". These social abuses can result in depression, loneliness, isolation, anxiousness and escalated tension amongst housing "members". Those most vulnerable or in need of social outlets are the most restricted by residing in this hall.

\section{PSYCHOLOGICAL HARMS AND INTERNALIZED OPPRESSIONS}

The psychological domination that happens at RMWP, as well as other women's penal institutions, includes authoritatively asserting what kind of relationships are appropriate for women - certainly excluding consensual relationships with other prisoners and also moralistically shunning queer relationships. For example, in some of the CBT classes, the stereotypical, traditional family structures are promoted. Women prisoners at RMWP are supposed to give a description of their childhood family dynamics or of the family they have made as an adult before entering prison and practitioners then compare it to the "traditional" heteronormative, nuclear family 
structure. This can reinforce feelings of shame and inadequacy. Women are not affirmed by the fact that nearly all family dynamics have problems which is normative, since most families experience various levels of abuse, substance addiction and other issues. Therefore, women prisoners are taught that they inherit a legacy of dysfunction and can even "pass it down" through their children. This iteration of the "culture of poverty" thesis - a school of thought asserting that marginalized mothers and/or family units instill cultural traits in children that are responsible for the perpetuation of poverty - presumes that poor, queer, or disadvantaged mothers are incapable of childrearing and fatalistically deficient (Lewis, 1959).

"Relationships" at RMWP are prohibited. Even if two people appear to be in a relationship or if staff members observe a relationship forming even platonic ones - they use tactics to dissolve it, including exclusive observation, physical separations, intimidation, and negative repercussions for otherwise minor behaviours. Prison guards and staff members have asserted that relationships are not allowed because women are unable and ill-prepared to manage them, despite any growth prisoners might acquire as a result of working through such emotional and psychological processes. Yet being able to experience the dynamics of relationships provides individuals with the skill set to heal and evolve. Since the vast majority of incarcerated women at RMWP have survived intimate partner violence, they need to heal these wounds and patterns. When prohibiting survivors of abuse the opportunity to exercise truly autonomous decision making processes, their wounds can be stifled into dormancy, which might then be compounded by additional institutional oppressions and, without the opportunity to work out one's process of self-assertion, women may be prohibited from empowering themselves through positive individual choice. A general sentiment among prison officials and therapeutic practitioners at RMWP is that they are making better people by forcing them to abstain from meaningful relationships and companionship. This strips women of a vital life-affirming process and experience. The consequences are evident in the way women at RMWP express feeling dead, shut off from emotional vitality, a feeling of "flatness", intolerance, "just existing", anxiety and a lack of empathy. Incarcerated women who deviate from the rules by developing a relationship have expressed feeling fully alive, despite the harsh treatment and grave consequences they receive from staff. Administrative and staff tactics can make the environment so intolerable and arbitrarily unbearable 
for prisoners to maintain meaningful relationships that they may ultimately sabotage themselves or devolve completely. Correctional staff engage in these abuses against the women at RMWP for simply being human and engaging in human behaviour.

We acknowledge that the Prison Rape Elimination Act (PREA) requires facilities to enforce a "zero-tolerance" level of sexual activity, and to therefore penalize any incident of sexual activity. However, PREA guidelines do not require prison officials to harass or discriminate against individuals who build meaningful (platonic or otherwise) relationships within their confined environment. PREA was instituted to eliminate incidences of sexual assault, whether it is through coercion, exploitation, force, domination or any other means. While sexual coercion and violence is not absent from women's institutions across the U.S., PREA was put into effect as a response to the prevalence of sexual violence within male institutions, and that of guards against prisoners in both men's and women's prisons. Institutions that use PREA as a platform for enacting extremely repressive social control strategies by enforcing restrictive environments are cutting people off from a highly beneficial part of their rehabilitation experience. Research demonstrates that women prisoners' self-worth and positive interpersonal skills are greatly improved when they can build positive relationships with their peers (Pollack, 2005). Therefore, a facility's preoccupation with, and fear of, the possible development of relationships interrupts this process and furthermore thwarts opportunities for growth and healing. It is clear that prison facilities are adopting genderresponsiveness programming for the sake of legitimating their institutions and disregarding the components of gender-responsive research that would conflict with their use of power and control. While relationships seem to be only a single aspect of institutional life, the overarching punitive response and attitude toward the core of this human element has observably become the driving force in creating an overall hostile, anxious, and oppressive atmosphere at RMWP and elsewhere.

In addition to regulating relationships, guards and staff members also restrict autonomous conflict resolution among prisoners. In CBT and in the prison regime, the assumption is that criminalized women are unable to resolve their own conflicts. Prison staff judge women as culturally deficient, which leads to their being heavily restricted from fully exercising their abilities to problem solve on their own. If staff members observe tension among women 
or a conflict arises, individuals are solely allowed to communicate or interact with staff mediation. This results in the practice of incarcerated women turning to staff members and prison guards to facilitate communication if they are experiencing an argument or overwrought situation. Not being encouraged to work this process out individually robs women of their emotional and psychological autonomy, and vital life-affirming skills:

After I arrived at RMWP I was shocked to realize that women couldn't even have a heated argument or blow off steam without being locked in their room on a temporary restriction order (TRO) and receiving an "insulting behaviour" write-up. I started to see that the fear of this consequence would incite women to prematurely involve staff in whatever the conflict was so as to either perhaps gain favor in their position or "get it over with" and get locked down. (Tara's personal observations, November 2015).

This is a clear example of regulating and defining femininity; raising one's voice, for example, and defending oneself can be a valuable skill, especially since incarcerated women consistently have to navigate disempowering spaces in their everyday lives. Yet gender-responsiveness pathologizes that skill, and instead promotes universal deference to authority and promotes a "respectable" version of middle-class white femininity. In addition to physically caging individuals, these two control tactics - banning relationships and managing conflict - incapacitate prisoners' abilities to engage in life in a healthy way.

Not only does psychological domination through genderresponsiveness deny women their autonomy, but it also creates and reinforces social hostility between incarcerated women and hierarchies among them. We will outline some of the emotional harms committed by prisoners against other prisoners, but we want to squarely place the source of this problem on RMWP staff and the penal-therapeutic regime. Because RMWP employs moralistic therapy and attempts to teach psychological "lessons", some women use the strategy of accommodating themselves to the power structure. Some women at RMWP, especially those serving longer sentences, fear risking their favourable or positive positions with the staff, and so they mould themselves into "model" prisoners. We want to assert that these model prisoners are not immune from the oppressive power regime in the prison; the model prisoners also 
experience great hardship by being incarcerated and are reacting to power in a way that might alleviate some of their burdens and gain approval in the process. A consequence of this accommodation, however, is that the model prisoners actively separate themselves from the deviants. In the study of prisoner categories and characteristic behavioural patterns, this upper echelon group of model prisoners is common within the prison setting. In the work of John Irwin and Donald R. Cressey (1962), this group is termed the "legitimate" subculture, since prison administrators characterize these prisoners as presenting few problems for the regime. These model prisoners conform to what they think administrators expect of "good" prisoners, maintain anti-criminal and anti-prisoner attitudes, familiarize themselves with staff, and subsequently become isolated from the rest of the prisoner population. This approach to doing time may result in accommodation, but it also has a problematic consequence regarding lateral oppression between model prisoners and other prisoners.

The model prisoners internalize the belief, to varying extents, that expressing one's self through anger or engaging in a meaningful relationship while in prison is inappropriate, wrong, and shameful. As a result, they echo the status quo ideologies and shun the deviant prisoners in order to sustain a rapport with staff and to keep their privileges. For example, some model prisoners might react to another person's write-up with a response like, "Well, you should stay out of trouble" or "You should do your time better". Model prisoners also associate noisy or busy housing areas as "immature", "obnoxious" or "negative". Noise, to the model prisoners, represents defiance to the institutional regime and therefore silence, or remaining subdued and docile, represents "doing one's time well". Model prisoners corroborate the hegemonic CBT model by assuming that a person's disciplinary action is of their own making, without contextualizing the problem as happening in an extremely restrictive and depraved prison environment that they are also subjected to. Moreover, they assert that relying on staff for conflict resolution is healthy and staff should be heavily involved in prisoners' daily lives. When prisoners heavily and loudly advocate for themselves, for example, model prisoners view them as being manipulative and provoking prison staff. In this way, model prisoners become complicit in their own captivity. Model prisoners also avow an idealized version of white femininity by promoting "subdued" and "mature" performances — namely that women be agreeable, quiet, compliant, deferential, and orderly. 


\section{CONCLUSION}

The belief that prison therapy teaches prisoners how to be responsible, productive citizens in society is a disservice to those who are incarcerated. Furthermore, it might actually make them unprepared for "real" life once released. The institutional denial of meaningful prisoner relationships and of individual conflict resolution might mean that an ex-prisoner has a reduced capacity to deal with the unpredictable changes of daily life once released. Moreover, gender-responsive psychological programming does not dismantle the substantive material inequalities that continue to persist. Such initiatives might lead to further marginalize people who are already vulnerable by leading them to believe that they are pathologically deficient for being forced into making compromised choices within a racist and economically exploitative system. We wish to critique not only the physical incapacitation that comes from prison cages, but also the psychological entrapment that happens when a system seeks to totally confine and control those ungovernable souls who do not submit to a violent social order.

Despite the possible negative effects of psychological domination, the women at RMWP (and beyond), including those in the most restricted and oppressive housing areas, are finding opportunities to not only survive but to thrive and cultivate emotional, psychological, spiritual, physical, and social well-being. They are finding opportunities for resistance by developing solidarity and making positive social change — whether it be through participating in peer-based activities, sharing personal knowledge, assisting one another with communication or grievance forms, or by simply holding an emotional space for another by listening to their experiences of personal turmoil and triumph. We hope to see more analyses of the varied ways in which prisoners resist psychological domination. Even though total control may be the goal of the prison state, it will not and cannot ever achieve such a dystopian end. Resilient and even defiant prisoners continue to resist, in even the bleakest of situations.

As the U.S. moves towards a so-called rehabilitative model and reconfigures its carceral regime, we believe it is important to critique therapeutic modalities, particularly gender-responsiveness, in addition to the other ways in which the penal state controls its wards. As the U.S. subtly and slowly starts to decarcerate and rely on alternatives to incarceration, we might witness an increase in mandated rehabilitation. 
And what might the greater implications be if entire swaths of marginalized groups are subjected to psychological programming and mental evaluations? Future research should be conducted into the types and consequences of the penal-therapeutic regime, including case studies and ethnographies conducted by prisoners. Therapeutic governance, including gender-responsiveness, is a cultural project that scrutinizes people and frames them as being disordered and pathological for existing outside of dominant ways of being. It blames individuals for being impoverished, for being subject to racialized social control and for being targets of gendered violence. We argue that state-controlled rehabilitation programs continue to ensnare marginalized populations into a net of social control that acts in conjunction with institutionalized racism, sexism, ableism and classism.

\section{ENDNOTES}

* Both authors contributed equally to this article. We made the political choice to list Tara Perry first for two reasons. First, Tara is the most impacted by the prison system and its power regime. Second, we want to subvert the assumption that Colleen Hackett, the non-incarcerated author with greater institutional resources and formal academic legitimacy, has more ownership over the final outcome. Lawrence and Dua's 2005 Social Justice article, entitled "Decolonizing Antiracism", inspired this choice.

1 We retain the use of third-person narration for the sake of continuity, though the following two analytic sections are informed by and rooted in the first author's experiences and observations. We include first-person excerpts from the first author's field notes.

2 We use pseudonyms for all institutional names.

\section{REFERENCES}

Belknap, Joanne (2015) The Invisible Woman: Gender, Crime, and Justice (4 ${ }^{\text {th }}$ edition), Stamford (CT): Cengage Publishing.

Bloom, Barbara, Barbara Owen, and Stephanie Covington (2003) "Gender-Responsive Strategies: Research, Practice, and Guiding Principles for Women Offenders", National Institute of Corrections Report, Washington (D.C.): U.S. Department of Justice.

Chesney-Lind, Meda (2002) "Imprisoning Women: The Unintended Victims of Mass Imprisonment", in Marc Mauer and Meda Chesney-Lind (eds.), Invisible Punishment: The Collateral Consequences of Mass Imprisonment, New York (NY): The New Press. 
Chesney-Lind, Meda and Lisa Pasko (2004) The Female Offender: Girls, Women, and Crime, Thousand Oaks (CA): Sage Publications.

Cohen, Stanley (1985) Visions of Social Control: Crime, Punishment, and Classification, Cambridge (UK): Polity Press.

Cruikshank, Barbara (1999) The Will to Empower: Democratic Citizens and Other Subjects, Ithaca (NY): Cornell Press.

Daly, Kathleen (1992) "Women's Pathway to Felony Court: Feminist Theories of Lawbreaking and Problems of Representation", Review of Law and Women's Studies, 2: $11-52$.

Dean, Mitchell (2010) Governmentality: Power and Rule in Modern Society ( $2^{\text {nd }}$ edition), Los Angeles (CA): Sage Publications.

Faith, Karlene (2011) Unruly Women: The Politics of Confinement \& Resistance $\left(^{\text {nd }}\right.$ edition), New York (NY): Seven Stories Press.

Foucault, Michel (1991) "Governmentality", in Graham Burchell, Colin Gordon and Peter Miller (eds.), The Foucault Effect: Studies in Governmentality, Chicago (IL): University of Chicago Press, pp. 87-104.

Hackett, Colleen (2013) "Transformative Visions: Governing through Alternative Practices and Therapeutic Interventions at a Women's Reentry Center", Feminist Criminology, 8(3): 221-242.

Hannah-Moffat, Kelly (2004) "Criminogenic Need and the Transformative Risk Subject: Hybridizations of Risk/Need in Penality", Punishment and Society, 7(1): 29-51.

Irwin, John and Donald R. Cressey (1962) "Thieves, Convicts, and the Inmate Culture", Social Problems, 10(2): 142-155.

Kilty, Jennifer (2012) “'It's Like They Don't Want You To Get Better': Psy Control of Women in the Carceral Context", Feminism \& Psychology, 22(2): 162-182.

Lewis, Oscar (1959) Five Families: Mexican Case Studies in the Culture of Poverty, New York (NY): Basic Books.

McCorkel, Jill (2013) Breaking Women: Gender, Race, and the New Politics of Imprisonment, New York (NY): New York University Press.

McKim, Allison (2008) “'Getting Gut-Level': Punishment, Gender, and Therapeutic Governance", Gender \& Society, 22(3): 303-323.

Owen, Barbara (1998) "In the Mix": Struggle and Survival in a Women's Prison, Albany (NY): State University of New York Press.

Pollack, Shoshana (2010) 'Labeling Clients 'Risky': Social Work and the Neo-liberal Welfare State”, British Journal of Social Work, 40: 1263-78.

Pollack, Shoshana (2005) "Taming the Shrew: Regulating Prisoners through WomenCentered Mental Health Programming", Critical Criminology, 13: 71-87.

Price, Joshua (2012) Structural Violence: Hidden Brutality in the Lives of Women, Albany (NY): State University of New York Press.

Richie, Beth (2012) Arrested Justice: Black Women, Violence, and America's Prison Nation, New York (NY): New York University Press.

Rose, Nikolas (1999) Governing the Soul: The Shaping of the Private Self (2 ${ }^{\text {nd }}$ edition), London (UK): Free Association Books.

Russell, Emma and Bree Carlton (2013) "Pathways, Race and Gender Responsive Reform: Through an Abolitionist Lens", Theoretical Criminology, 17(4): 474-492.

The Sentencing Project (2016) Incarcerated Women and Girls. Washington, D.C. 
Wall, Sarah (2008) "Easier said than Done: Writing an Autoethnography", International Journal of Qualitative Methods, 7(1): 38-53.

Wattanaporn, Katelyn and Kristy Holtfreter (2014) "The Impact of Feminist Pathways Research on Gender-Responsive Policy and Practice”, Feminist Criminology, 9(3): 191-207.

\section{ABOUT THE AUTHORS}

Tara Perry is from Colorado and is currently completing her bachelor's degree in Sociology and Business. This critique emerged while finishing the remaining two years of her 17-year sentence in an out-of-state prison. While in prison, Tara led and facilitated several anti-violence workshops, engaged in trauma work with her peers and became an expert dog trainer.

Colleen Hackett, $P h D$ is a formerly incarcerated organizer, scholar and educator based out of the Colorado State University in Pueblo. Colleen facilitates a political education class at a woman's prison called Webs of Support and edits a prisoner publication entitled unstoppable! that is by and for U.S.-based prisoners who identify as women, transwomen, and gender non-conforming (unstoppable! publication, PO Box 11032, Pueblo, CO 81001 // unstoppable.noblogs.org). 